\title{
Retroperitoneal Paraganglioma: Olgu Sunumu
}

\section{Retroperitoneal Paraganglioma: A Case Report}

\author{
Dr. Serdar Çelik1, Dr. Ömer Demir1, Dr. Burçin Tuna2, Dr. Kutsal Yörükoğlu2, Dr. Adil Esen1 \\ ${ }^{1}$ Dokuz Eylül Üniversitesi Tıp Fakültesi, Üroloji Anabilim Dalı, Izmir, Türkiye \\ 2Dokuz Eylül Üniversitesi Tıp Fakültesi, Patoloji Anabilim Dalı, Izmir, Türkiye
}

\section{Özet}

Retroperitoneal paragangliomalar nadir görülen nöral krest orjinli nöroendokrin tümörlerdir. Çoğunlukla benign tümörlerdir, fakat malign olanları agresif seyredebilir ve metastaza yol açabilir. Retroperitoneal paragangliomaların temel tedavi seçeneği kitlenin komplet rezeksiyonudur. Cerrahi sonrası malignite potansiyeli açısından takip önemlidir. Bu yazıda 18 yaşında, sağ böbrek anteriorunda $8,5 \mathrm{~cm}$ kitle saptanan ve cerrahi olarak eksize ettiğimiz kadın hastayı sunmayı amaçladık. (Üroonkoloji Bülteni 2014;13:184-186)

Anahtar Kelimeler: Feokromasitoma, nonfonksiyone paraganglioma, nöroendokrin tümör, retroperitoneal paraganglioma

\begin{abstract}
Summary
Retroperitoneal paragangliomas are rare neuroendocrine tumors of neural crest origin. They are mostly benign, however; malignant tumors may present aggressive behavior and may lead to metastasis. Complete surgical resection of the mass is the only potential curative treatment modality for retroperitoneal paragangliomas. Postsurgical follow-up is important for malignant potential. Here we report a case of a 18 year-old female with an $8.5 \mathrm{~cm}$ mass located anterior of the right kidney, treated by complete surgical excision. (Bulletin of Urooncology 2014;13:184-186)
\end{abstract}

Key Words: Pheochromocytoma, nonfunctional paraganglioma, neuroendocrine tumor, retroperitoneal paraganglioma

\section{Giriş}

Ekstraadrenal feokromasitoma veya paraganglioma az rastlanan nöroektodermal tümörlerdir. Paragangliomalar kromaffin doku ile ilişkili tümörlerin \%10-\%20'sini oluştururlar. Paraganglial dokunun bulunduğu her yerde gelişebilirler (1). Olguların yaklaşık \%10'u ekstraadrenal kaynaklı olup en sık batın, toraks ve boyun bölgesinde görülür (2). Retroperitoneal paragangliomalar, genelde çocuk yaşlarda ortaya çıkar. Bunların \%40-\%50'si malign olup genelde yavaş progresyon gösterirler ve çoğu fonksiyoneldir (3). Fonksiyona bağlı olarak oluşan çarpıntı, hipertansiyon atakları, baş ağrısı, yüzde kızarıklık ve kilo kaybı gibi semptomlar tanıda önemlidir (4).

$\mathrm{Bu}$ yazıda pararenal kitle ile başvuran ve patoloji sonucu retroperitoneal paraganglioma olarak raporlanan hastaya cerrahi öncesinden cerrahi sonrası 3. yıl kontrolüne kadar olan uzun süreli yaklaşımımızı sunmayı amaçladık.

\section{Olgu Sunumu}

Sağ yan ağrısı nedenli yapılan tetkiklerinde sağ pararenal kitle saptanan 18 yaşında bayan hasta kliniğimize başvurdu.
Görüntüleme tetkiklerinde sağ böbrek anterior kesimde, hilusla komşuluk gösteren ve proksimal üreterle invazyon açısından kuşkulu alanlar taşıyan $8 \mathrm{~cm}$ hipervasküler kitlesel lezyon saptandı (Resim 1A ve 1B). Hastanın özgeçmişinde ve fizik muayenesinde ek patoloji saptanmadı.

Hastanın yapılan laboratuvar incelemelerinde mikrositer anemi mevcuttu. Hormon aktif paraganglioma şüphesi ile yapılan bazal kortizol ve adrenokortikotropik hormon (ACTH) ölçümleri sıra ile $25,9 \mu \mathrm{g} / \mathrm{dL}$ ve $29,4 \mathrm{pg} / \mathrm{mL}$ olarak saptandı. Kortizol değerindeki minimal yükseklik nedenli $1 \mathrm{mg}$ deksametazon supresyon testi yapıldı. 26,6 $\mu \mathrm{g} / \mathrm{dL}$ olan kortizol değeri anlamlı olarak değerlendirilmedi. Yapılan 24 saatlik idrar tetkiklerinde vanilmandelik asit (VMA), homovalinik asit (HVA), 5-hidroksi indol asetik asit (5-HIAA), metanefrin ve normetanefrin değerleri normal olarak saptandı. Bu bulgularla klinik olarak nonfonksiyone paraganglioma olarak değerlendirilen olguda eksplorasyon kararı alındı.

Sağ flank insizyon ile yapılan eksplorasyonda sağ renal hilus düzelinden başlayan böbrek ile bağlantısı olmayan, orta hatta ve inferiora doğru uzanan $9 \mathrm{~cm}$ 'lik kitle gözlendi. Kitlenin 


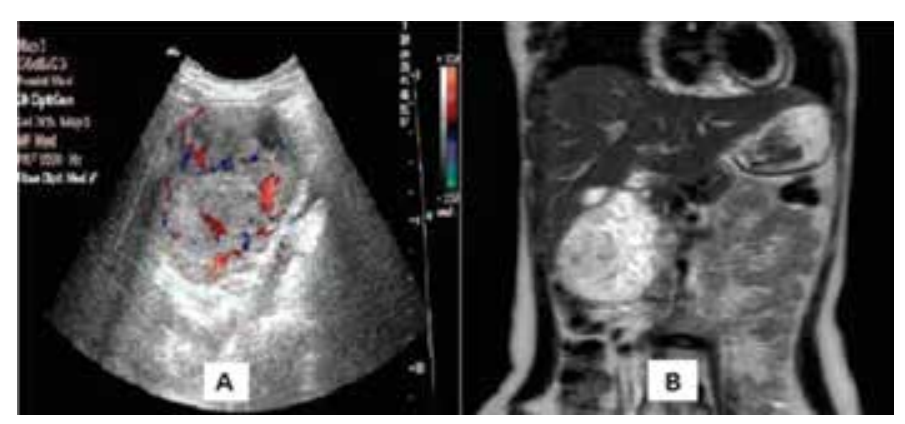

Resim 1. A) Tümörün ultrasonografideki hipervasküler görünümü B) Tümörün MRI görünümü

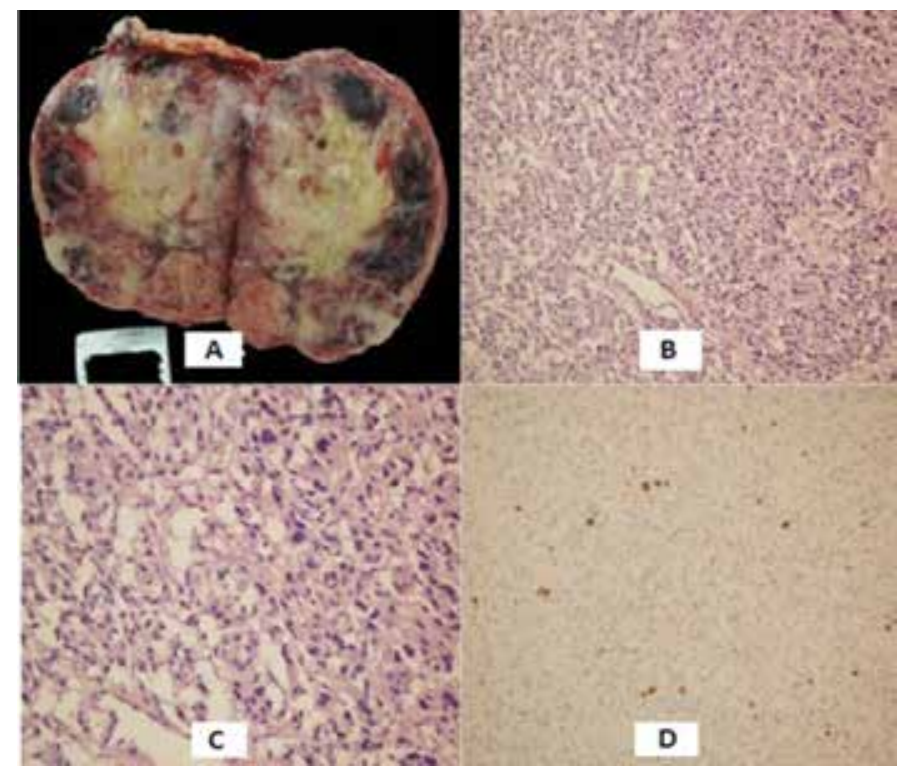

Resim 2.A) Tümörün makroskopik görünümü B) Mikroskopik olarak tümörde atipi gösteren alan (H\&E, x200) C) Resim 2B'de izlenen atipik alanın büyük büyütmede görünümü (H\&E, x400) D) Tümörde Ki-67 indeksi

direkt sağ renal venden 1 adet, vena cava inferiordan 3 adet ve aortadan 3 adet vasküler dal aldığı gözlendi. Bu vasküler bağlantılar kesildi. Kitlenin superiordan ve inferiordan 2 adet pedikülü de kesilerek kitle enblok olarak çıkartıldı ve operasyona son verildi. Peroperatif 2 ünite eritrosit süspansiyonu verilen hastada herhangi bir komplikasyon olmadı.

Postoperatif patolojik incelemede doku 145 gr ağırlığında, $8,5 \times 7 \times 4 \mathrm{~cm}$ boyutlarında, damarlanması yoğun olarak gözlenebilen, kapsüllü, kanama alanları içeren tümör gözlendi (Resim 2A). Mikroskopisinde tümör, fibrovasküler psödokapsül ile çevriliydi. Tümör hücreleri geniş eozinofilik sitoplazmalı, nükleer psödoinklüzyonlar ve Peryodik Asit Shift (PAS) pozitif sitoplazmik globüller içerir nitelikteydi. Yer yer miksoid stroma, kanama alanları gözlenen tümörde bazı alanlarda belirgin nükleer atipi, multinükleer hücreler ve yüksek mitotik aktivite dikkati çekmekteydi (Resim 2B, 2C). Tümör hücreleri immünohistokimyasal olarak vimentin ile diffüz, CD10 ve kromogranin ile fokal boyanırken, NSE, sinaptofizin ve keratin,
EMA, HMB45 ve aktin ile boyanma saptanmadı. S-100 ile sustentaküler hücreler boyandı. Ki-67 indeksi \%10 olarak saptandı (Resim 2D). CD117 ile nonspesifik boyanma gözlenmiştir. $\mathrm{Bu}$ özellikleri ile birlikte tümör retroperitoneal paraganglioma (ekstraadrenal feokromasitoma) olarak değerlendirildi.

Hastanın postop 24 saatlik idrarda vanilmandelik asit (VMA), 5-hidroksi indol asetik asit (5-HIAA), homovalinik asit (HVA), metanefrin ve normetanefrin değerleri normal epinefrin ve norepinefrin değerleri düşük olarak saptandı. Yine postoperatif görüntüleme yöntemlerinden meta-iyodobenzilguanidin (MIBG) sintigrafisi ve 6 aylık torakoabdominal BT'lerinde patoloji saptanmadı. Takibinin 3. yılında nüks ya da metastatik lezyon saptanmayan hasta stabil bulgularla izlenmektedir.

\section{Tartışma}

Retroperitoneal paragangliomalar, çocuk yaşlarda ortaya çıkan, \%15-\%24'ü fonksiyonel (feokromasitoma), \%15-\%24'ü multisentrik, \%40-\%50 oranında malign ve yavaş progresyon gösteren tümörlerdir $(3,5)$. Primer tümörün yavaş büyüme özelliğinden dolayı primer tümöre bağlı ölüm nadirdir (6). Tümörün fonksiyonel özelliğinin belirlenmesi için operasyon öncesi 24 saatlik idrarda VMA, 5-HIAA, HVA, metanefrin ve normetanefrin değerleri araştırılmalıdır. Bu doğrultuda yapmış olduğumuz 24 saatlik idrar sonucuna göre olgumuzda nonfonksiyone paraganglioma düşünülmüştür. Tümörün multisentrik olabilme özelliğinden dolayı postoperatif 6. ayda MIBG sintigrafisi ile tarama yapılmıştır. Olgumuzda ek odak saptanmamıştır.

Retroperitoneal paragangliomalar, genelde abdominal aorta ve Vena Cava İnferior arasında, bu iki yapıya genelde invazyon göstermeyen bir konumda bulunurlar. Dikkatli ve özenli bir diseksiyonla, bu yapılardan ayrılıp total eksizyonu mümkün olabilir (3). Olgumuz tanımlamalara uygun özellikler sergilemekteydi.

Klinikte nonfonksiyonel tümör olarak görülebilen paragangliomalar, malign davranışlı tümörlerdir ve maligniteyi belirleyen tek kriter metastaz varlığıdır. Sıklıkla geç metastazlar görülür. Hematojen veya lenfojen yayılım gösteren bu tümörler, en sık lenfnodları, kemik, akciğer ve karaciğere metastaz yapar. Metastaz oluştuktan sonra ortalama yasam süresi genellikle üç yıldan azdır (7). Malign paragangliomaların tedavisinde öncelik kitlenin eksizyonudur (8). Komplet rezeksiyona ragmen \%8-\%20 oranında nüks, \%28-\%50 oranında metastaz gelismektedir (9). Metastaz dışında maligniteyi belirleyen kesin morfolojik kriter bulunmamaktadır. Maligniteyi öngören kriterler ekstraadrenal yerleşim, kaba nodülarite, yaygın nekroz, hyalen globüllerin olmayışı, genç yaş, tümör boyutu ve Ki-67 indeksi olarak özetlenebilir. Olgumuzda kötü prognostik faktörler genç yaş, ekstraadrenal yerleşim, tümörün çapı, yüksek Ki-67 indeksi ve mitotik aktivite ile fokal nükleer atipidir.

Sonuç olarak olgumuzda 3 yıllık izlem sonucunda herhangi bir metastaz bulgusu saptanmamıştır. Nadir görülen bu tümörlerde fonksiyonu belirleme açısından preoperatif hormonal değerlendirme ve olası nüksler ve geç dönem metastaz riski açısından da postoperatif takip ön plana çıkmaktadır. 
Çıkar çatışması: Yazarlar bu makale ile ilgili olarak herhangi bir çıkar çatışması bildirmemişlerdir.

\section{Kaynaklar}

1. Cunningham SC, Suh HS, Winter JM, et al. Retroperitoneal paraganglioma. single-institution experience and review of the literature. J Gastrointest Surg 2006;10:1156-1163.

2. Somasundar P, Krouse R, Hostetter R, et al. Paragangliomas- a decade of clinical experience. J Surg Oncol 2000;74:286-290.

3. Grant CS. Pheochromocytoma. In: Textbook of Endocrine Surgery. 1st ed. ed(s). Clark OH. Philadelphia. W.B.Saunders, 1997:513-528.

4. Elder EE, Elder G, Larsson C. Pheochromocytoma and functional paraganglioma syndrome: no longer the $10 \%$ tumor. J Surg Oncol 2005;89:193-201.
5. Kudoh A, Tokuhisa Y, Morita K, et al. Mesenteric paraganglioma: Report of a case. Surg Today. 2005;35:594-597.

6. Massey V, Wallner K. Treatment of metastatic chemodectoma. Cancer 1992;69:790-792.

7. Yurt A, Arda MN, Vardar E. Metastatic pheochromocytoma of the thoracic spinal extradural space. Case report and review of the literature. Kobe J Med Sci 2005;51:49-53.

8. Robert $\mathrm{O}$, Louis R. Malignant paraganglioma of the posterior mediastinum. A case report and review of the literalure. Caner 1990;65:564-569.

9. Nap RR, Meinardi JR, van den Berg G, et al. Longterm follow-up is indicated after surgery for a phaeochromocytoma. Ned Tijdschr Geneeskd 2006;150:1045-1049. 